\section{6: The year of Phlebological Olympic Games}

\author{
Paolo Zamboni \\ Department of Morphology, Surgery, and \\ Experimental Medicine; Vascular Diseases \\ Center and Section of Translational \\ Medicine and Surgery, University of \\ Ferrara, Italy
}

Summer 2016, the Summer of the Olympic Games, reserves challenging news also in the field of venous and lymphatic diseases. The editorial would make the point, while updating friends and colleagues.

The market increasingly pushes the endovascular handling of varicose veins. Stripping is killed and even CHIVA shows a tendency to move forward intravascularly. ${ }^{1-3}$ Thermal laser or radio - frequency techniques have now been able to supplant the traditional surgical techniques and turn the preference of surgeons toward them.,2 They are ablative techniques that do not involve the surgical incision and overcome any previous problem stripping-related by the means of standardized tumescence anesthesia. In addition, the office independent feasibility of tumescent thermal ablation makes both approaches preferable to stripping. ${ }^{1,2}$

However, even the tumescence is likely to be overcome by the surgical glue, leading to a scenario unthinkable only few years ago. Summer 2016 introduces to the phlebological community the WAWES study, very exciting for everybody who are fanatic of the 1000 ways to cook the saphenous vein. Recent introduction of the endovascular glue will lead toward office saphenous vein ablation, non-thermal, nontumescent, non postoperative compression. Certainly a big achievement in the field, something like the new Olympic record in varicose veins treatment.

The WAVES trial is a single-centre study evaluating the VenaSeal system in the treatment of one or more incompetent $\mathrm{N} 2$ veins (greater saphenous vein, small saphenous vein or anterior accessory saphenous vein) with no postoperative compression stockings. The trial enrolled 50 patients and data were presented at the EVF meeting in London last July. ${ }^{4}$

Medtronic and the PI Gibson have not had the patience to wait for a more prolonged and significant follow-up for a chronic disease, and in London we were informed that at one month they recorded $100 \%$ of successful procedures, equaling the world record set by all the competitors procedures.

One of the funniest aspects introduced by the use of intravenous techniques are represented by the recommendation for their proper use. For example, it should not be used when the saphenous vein has a diameter between that of a python and that of an anaconda, is twisted like a sleeping rattlesnake, and it is even complicated by an ulcer.

From this point of view WAVES trial differs from the VeClose trial, which compared cyanoacrylate embolization and radiofrequency ablation for incompetent great saphenous veins. In the WAVES trial the human limits were abundantly passed, veins up to $20 \mathrm{~mm}$ were allowed, compared to $12 \mathrm{~mm}$ for VeClose, and also multiple segments were treated in the same session, and no compression stockings were used postoperatively. In the WAVES trial even the challenging CEAP clinical class 5 was allowed to be treated. ${ }^{4}$

The mirage of treating varicose vein intravascularly without any anesthesia has prompted numerous phlebologists to propose other personal techniques. Then here Frullini proposes Holmium laser technology that delivers a so lower energy that do not require tumescent anesthesia. ${ }^{5,6}$ Given that this technology respects endothelium and does not obliterate the saphenous vein, this author proposes to finally obtain the obliteration using the Tessari foam. Just the latter together with Zini, quite the contrary, proposes to use at the beginning of the procedure the endovascularvapplication of foam sclerotherapy followed by the boiled interaction of Holmium laser. ${ }^{7}$ Anyway, both procedures are cheaper respect to current cyanoacrylate market cost, and lead to minimally thermal non-tumescent, success-

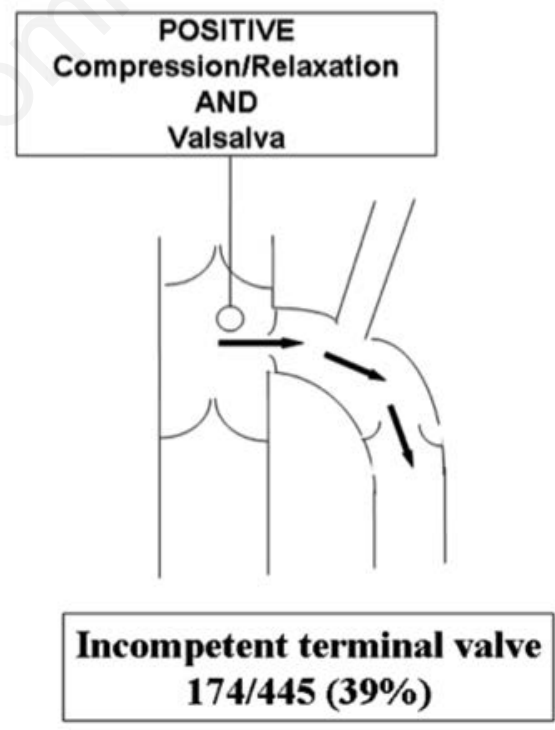

Figure 1. Ultrasound preoperative assessment of the saphenous terminal valve, as described in reference 8. Doppler sample volume herein represented by a circle, have to be placed on the femoral side of the junction. Evaluation requires both Valsalva and squeezing reflux elicitation manoeuver. Sisty-one percent of pattients exhibited no reflux at both or at one of the two manoeuvers and were considered with competent terminal valve. The same patients when examined with squeezing at the saphenous side of the valve showed reflux in $100 \%$ of cases. Reflux at both manoeuvers at both sides of the terminal valve were detected in the remaining $39 \%$ of patients with valve incompetence.

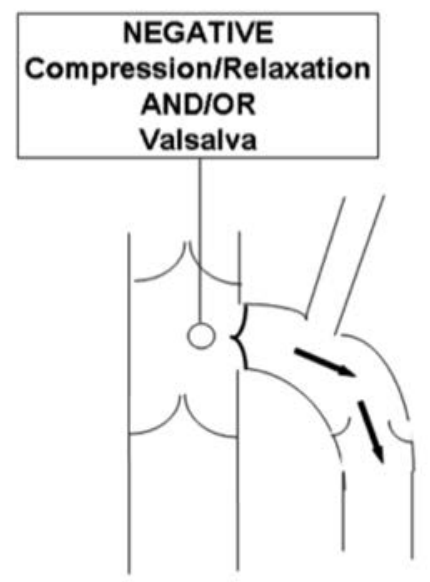

Correspondence: Paolo Zamboni, Vascular Diseases Center, University of Ferrara, AO S. Anna, via Aldo Moro 8, 44124 Loc. Cona, Ferrara, Italy.

E-mail: paolozamboni@icloud.com

Received for publication: 28 Augusst 2016

Revision received: 13 September 2016.

Accepted for publication: 13 September 2016. Attribution 4.0 License (by-nc 4.0).

(C) Copyright P. Zamboni, 2016

Licensee PAGEPress, Italy

Veins and Lymphatics 2016; 5:6249

doi:10.4081/vl.2016.6249

fully office saphenous vein closure.

What no one openly confesses in these studies is that varicose veins, which are the main problem, continue to be complementary treatd with two old office based techniques, both non-thermal and non tumescent: the . All the technological effort is focused on how to out the saphenous vein without anyone vicinity of our operating room, as well.

However, the main point still remains the fact that at least $50 \%$ of varicose patients (Figure 1). ${ }^{8}$ In these cases, an accurate preoperative ultrasound study allows to efficiently

\section{Competent terminal valve $271 / 445(61 \%)$}

This work is licensed under a Creative Commons 
expensive in approximately half the cases. Is select patients for office-based saphenous vein sparing techniques, like CHIVA2 or Muller/ASVAL. Correct preoperative ultrasound selection permits to sparing surgery to be absolutely competitive at 3 years in terms of recurrences. ${ }^{8}$

There are also ethical considerations in the overtreatment of the saphenous vein, a vessel that can potentially be saved not only for limb drainage but also for its potential use as a vascular graft. It has been recently shown that surgical correction of the bidirectional flow that characterizes the phenomenon of reflux, alone is able either to efficiently reduce the cross sectional area of the vein or especially to correct the inflammatory phenotype that distinguishes chronic venous disorders. ${ }^{9}$ In addition to this there are economic considerations. The use of techniques such as Muller/ASVAL or CHIVA 2 in about $50 \%$ of patients is certainly less expensive than endovascular treatments, with great benefit for patients and also for the economic management of the surgical activity both in private practice and in Countries with NHS. This means that saphenous ablation is unfair and

\section{this a good Science?}

\section{References}

1. Fernando RSW, Muthu C. Adoption of endovenous laser treatment as the primary treatment modality for varicose veins: the Auckland City Hospital experience. N Zeal Med J 2014;127:1399.

2. Lin JC, Nerenz DR, Migliore P, et al. Cost analysis of endovenous catheter ablation versus surgical stripping for treatment of superficial venous insufficiency and varicose vein disease. J Vasc Surg Venous Lymphat Disord 2014;2:98-103.

3. Gianesini S, Menegatti E, Zuolo M, et al. Feasibility of endovenous laser in type I CHIVA procedure: a new minimally invasive and saphenous paring therapeutic option. Veins and Lymphatycs 2015;4:5246.

4. Vascular News. WAVES trial shows $100 \%$ vein closure at one month with short return to work and normal activities. Available from: http:/vascularnews.com /waves-trialshows-100-vein-closure-at-one-monthwith-short-return-to-work-and-normalactivities/ Accessed: August 16, 2016.

5. Frullini A, Fortuna D. Laser assisted foam sclerotherapy (LAFOS): a new approach to the treatment of incompetent saphenous veins. Phlebologie 2013;66:51-4.

6. Gianesini S, Gafà R, Occhionorelli $\mathrm{S}$, et al. Histologic and sonographic features of holmium laser in chronic venous disease treatment. Int Ang 2016 [Epub ahead of print].

7. Zini F, Tessari L, Torre R. Sclerofoam assisted laser therapy for saphenous refluxes: an innovative tumescence-free technique Veins and Lymphatics 2015;4:5141.

8. Zamboni P, Gianesini S, Menegatti E, et al. Great saphenous varicose vein surgery without saphenofemoral junction disconnection. Br J Surg 2010;97:820-5.

9. Zamboni P, Spath P, Tisato V, et al. Oscillatory flow suppression improves inflammation in chronic venous disease. $\mathrm{J}$ Surg Res 2016;205:238-45. 